${ }^{1}$ Department of Nursing and Midwifery, Shoushtar faculty of Medical Sciences, Shoushtar, Iran

2Department of Operation Room, Paramedical faculty, Ilam University of Medical Sciences, Ilam, Iran

${ }^{3}$ Department of Nursing and Midwifery, Neyshabur University of Medical Sciences, Neyshabur, Iran

${ }^{4}$ Department of Health Services Management, School of Health, Ahvaz Jundishapur University of Medical Sciences, Ahvaz, Iran

${ }^{5}$ Department of Public Health, Shoushtar Faculty of Medical Sciences, Shoushtar, Iran

${ }^{6}$ Department of Public Health, School of Paramedical and Health, Zanjan University of Medical Sciences, Zanjan, Iran

\title{
Effectiveness of nutrition education and counseling on metabolic control parameters of diabetes mellitus type 2 patients in primary health care centers
}

\begin{abstract}
Introduction. Diet compliance is an essential part of the treatment and control of diabetes. The present study aimed to determine the effectiveness of education and face to face diet counseling on metabolic control parameters of patients with type 2 diabetes in primary health care centers.

Material and methods. This quasi-experimental study was conducted on 90 T2DM patients who referred to Andimeshk community health centers in 2018. Patients were randomly divided into two intervention $(n=45)$ and control ( $n=45$ ) groups. Data were analyzed by independent t-test, paired t-test and Chi-square using SPSS-18 software.
\end{abstract}

Results. Sixteen weeks after the implementation of the nutrition education and counseling program, there was a significant decrease in the clinical, anthropometric, and biochemical parameters of the intervention group $(P<0.001)$. However, none of the parameters were significantly decreased in the control group ( $P>0.05$ ). Conclusion. The research findings show that the implementation of group education program, along with

\footnotetext{
Address for correspondence:

Ahmad Moradi

Department of Public Health

Shoushtar Faculty of Medical Sciences, Shoushtar, Iran

Phone: +989371918485

e-mail: moradi-a@ajums.ac.ir, a_moradi1393@yahoo.com,

h.jalilian2019@gmail.com

Clinical Diabetology 2020, 9; 5: 293-299

DOI: $10.5603 /$ DK.2020.0030

Received: 26.04.2020

Accepted: 23.06 .2020
}

individual nutrition counseling, is very effective and can lead to weight loss, improved blood pressure and better control of blood glucose and lipids in T2DM patients. Therefore, the combination of education and counseling as two complementary methods in the treatment and control of diseases such as diabetes seems essential and effective. (Clin Diabetol 2020; 9; 5: 293-299)

Key words: type 2 diabetes, metabolic control, education, counseling, nutrition, primary health care

\section{Introduction}

Diabetes mellitus type 2 (T2DM) is considered one of the biggest problems of public health around the world $[1,2]$, imposing a tremendous direct and indirect costs on health care systems [3]. According to the International Diabetes Federation (IDF) report in 2015, about 415 million people in the world are diagnosed with diabetes, which is expected to increase to 642 million by 2040 , as well as the number of diabetic patients in Iran will reach 6 million people by 2030 [4].

The most important complications of type 2 diabetes include retinopathy, nephropathy, cardiovascular diseases, neuropathy, foot ulcer, amputations, and depression [5, 6]. These complications result from inadequate control of blood glucose and lifestyle [7].

T2DM patients need to be educated and counselled on how to prevent both acute and chronic complications common in diabetes to obtain desired glycemic control and improve their quality of life [8]. One of 
the most important factors in metabolic control and treatment of diabetic patients is dietary observation and dietary habits modifications $[3,9]$.

Nutritional treatment is an essential component of the program for people with diabetes. Using nutritional methods is a cost-effective economic solution to reduce complications and mortality rate caused by diabetes. Nutrition therapy should be tailored according to the goals and needs of each patient. In addition, educating the patient about how to implement it is just an important part of the nutrition management program [10]. Therefore, T2DM patients need to be referred to a dietitian after a diagnosis of a disease in order to determine a healthy and flexible lifestyle program tailored to their lifestyles [11]. Nutrition education is a must-see for these patients, given the major contribution to treatment and disease control [12]. A patient is the most important member of the diabetes care team and patient education is part of the care unit for diabetics [13].

Favorable diabetes management should lead to health behaviors in patients, which requires education and development of skills and motivation [14]. But knowledge alone does not guarantee health behaviors [15]; to succeed in this area, counseling, self-care education, and patient continuous follow-up are necessary [14]. However, in educational methods, less attention has been paid to motivating, improving the decision-making process, and determining the goals, while self-care of these patients is influenced by motivation, goal-setting, and decision-making. Clinical and healthcare counseling plays an important role in the management of chronic diseases, considered as the basis of diabetes management. Patients should be able to make the right decisions, learn applied skills in relation to their illness, and ultimately be able to take a good care of yourself. The counseling of life expectancy in these patients develops and strengthens their coping mechanisms [16]. The present study aimed to assess the effectiveness of nutrition counseling and education on improvement of the status and metabolic control of T2DM patients in Andimeshk, Iran.

\section{Methods}

This quasi-experimental study was conducted on 90 T2DM patients (intervention [ $n=45]$ and control [n $=45$ ] groups) who were randomly selected from two health centers of the community health centers in Andimeshk suburbs, Iran from May to November 2019 (Fig. 1). Inclusion criteria consisted of age range from 30 to 60 years, at least 1 year after diabetes diagnosis, lack of mental illness, non-serious complications of diabetes (kidney, liver, cardiovascular, stroke, etc.), under treatment with oral hypoglycemic drugs, no previous training in this regard, and willingness to participate in the study.

Moreover, exclusion criteria were no willingness to participate in the study, insulin therapy, severe physical inability, use of weight-losing or weight-gaining drugs, pregnancy, and no presence in two or more educational sessions. The data used in this study were collected in two stages at the beginning of the intervention and four months after the last counseling session, consisting of:

1. The demographic characteristics questionnaire including age, gender, marital status, employment status, education level, family income status, and duration of diabetes;

2. Blood pressure measurement: patients' systolic blood pressure (SBP) and diastolic blood pressure (DBP) were measured and registered by nurses based on the guidelines recommended in the blood pressure chart;

3. Anthropometric measurements: for measuring patients' body mass index (BMI), weights and heights using a scales and gauge with a precision of $0.5 \mathrm{~kg}$ and $0.1 \mathrm{~cm}$ respectively in a state of standing, no shoe, any cover over the head (such as hat) and with the minimum dress based on the formula $\mathrm{BMI}=$ body weight $[\mathrm{kg}] /$ height $\left[\mathrm{m}^{2}\right]$ was calculated:

4. Biochemical measurements: biochemical parameters in this study include hemoglobin $A_{1 c}\left(H_{b A_{1 c}}\right)$, fasting blood sugar (FBS), low-density lipoprotein $(\mathrm{LDL})$, high density lipoprotein (HDL), triglyceride (TG), and total cholesterol (TC). Patients were referred to a pre-designated laboratory for these tests. $\mathrm{HbA}_{1 \mathrm{c}}$ was measured by colorimetric method and the rest by an enzymatic method.

The intervention was conducted in two forms of group education and individual counseling for the intervention group by two nutritionists. The control group did not receive any training and only received routine care, but after the end of the program, the summary of educational materials was delivered to them as a pamphlet. At first, the intervention group was divided into three 15-participant subgroups. For each subgroup, 3 sessions of 90 minutes were held in 2 weeks. One of the challenges is learning the difference between people in learning method. Therefore, in order to increase the effectiveness of intervention, educational topics were presented in various ways such as clip, posters, booklets, lectures and group discussions. Then face-to-face individual counseling was done by a nutritionist based on the needs, eating habits, and health conditions of each patient in two 45-minute ses- 


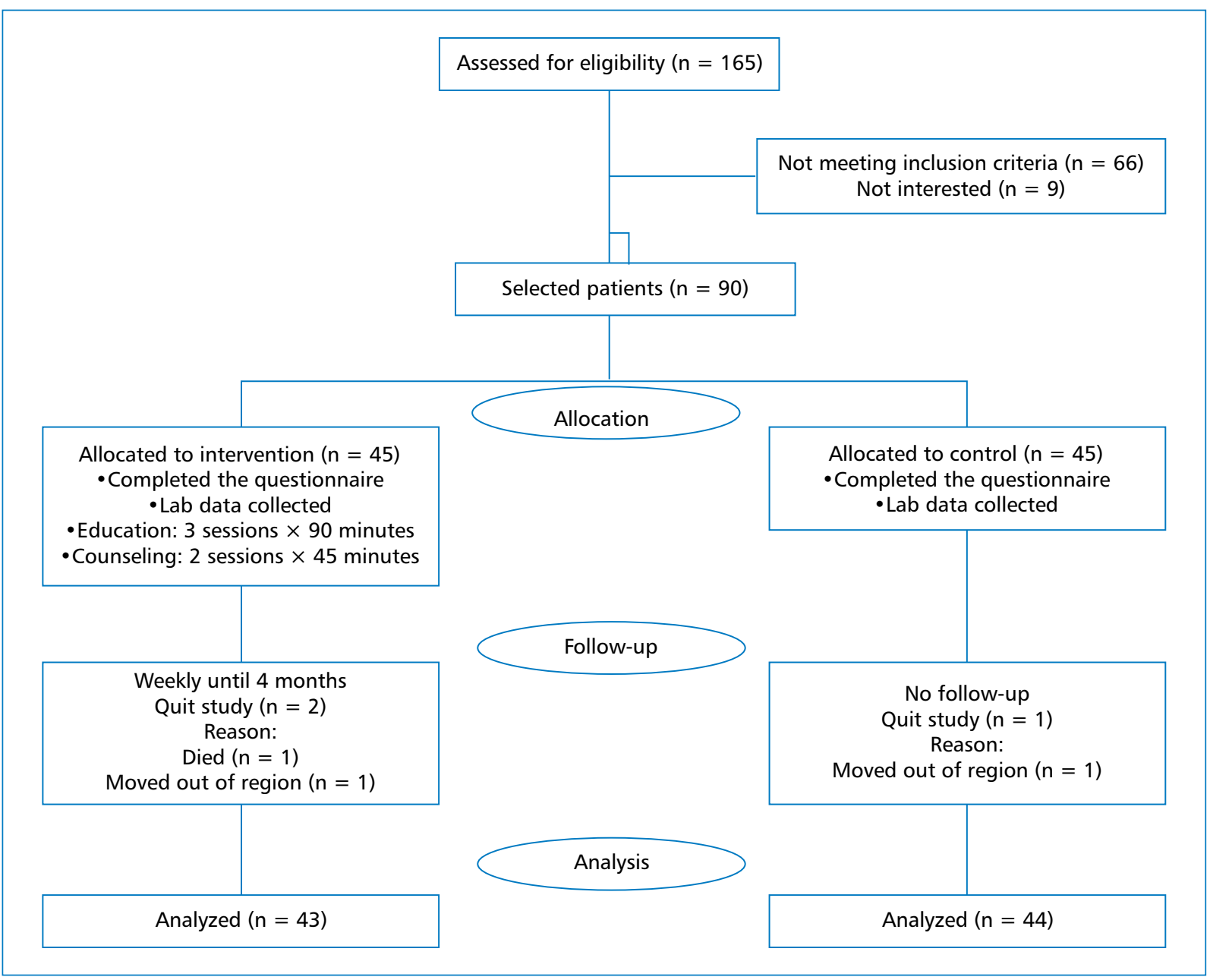

Figure 1. Flowchart of participations' selection for study

sions (weekly one session) and a nutrition program was presented. Educational content on healthy nutrition methods includes nutritional patterns with emphasis on balance and diversity and diet, high risk nutritional behaviors, pheromone recognition and how to use it, healthy eating plate, familiarity with harmful foods for diabetics and how to replace them with appropriate foods, advice on how to prepare and cook healthy foods, snacks, out-of-home eating strategies (restaurants, parties, on holidays), over-the-counter prevention methods, adherence to the diet plan, and advice on walking and physical activities that were prepared on the basis of the Ministry of Health's Guidebooks and other authoritative scientific sources $[17,18]$.

Moreover, in order to continue education, the contents of the pamphlet and pocket booklet about patients' nutrition were given to the patients in the intervention group. Patients in the intervention group were followed up for a period of 4 months by a nutritionist via telephone on a weekly basis to ensure the correct implementation of the programs. During this time, monthly brief counseling was also provided for the individuals with ambiguity in their schedules to correct the problems and modify their schedules, if necessary. They were asked to carefully follow the proposed diet until the end of the study, not to change it or to not start a new diet, and to report any changes in the type and amount of consumed medication.

The data were analyzed by SPSS software version 18 and Chi-square test, independent $t$-test, ANOVA, and paired $t$-test. The significance level was considered to be $<0.05$.

\section{Ethics approval}

The present research was approved with code IR.SHOUSHTAR.REC.1399.012 at the Ethics Committee of Shoushtar faculty of Medical Sciences.

\section{Results}

A total of 90 T2DM patients participated in this study, among which 87 participants (43 in the intervention group and 44 in the control group) completed the 
Table 1. Baseline demographic characteristics of intervention and control groups

\begin{tabular}{|c|c|c|c|c|}
\hline Variable & & $\begin{array}{l}\text { Intervention group }(n=43) \\
(\text { mean } \pm S D) \text { or } n(\%)\end{array}$ & $\begin{array}{l}\text { Control group }(n=44) \\
(\text { mean } \pm \text { SD) or } n(\%)\end{array}$ & P-value \\
\hline Age (years) & & $53.13 \pm 6.43$ & $50.82 \pm 6.17$ & $0.810^{*}$ \\
\hline \multirow[t]{2}{*}{ Gender } & Male & $22(51.2)$ & $24(54.5)$ & \multirow{2}{*}{$0.338^{* *}$} \\
\hline & Female & $21(48.8)$ & $20(45.5)$ & \\
\hline \multirow[t]{2}{*}{ Marital status } & Married & $40(93)$ & $43(98)$ & \multirow{2}{*}{$0.781 * *$} \\
\hline & Single & $3(7)$ & $1(2)$ & \\
\hline \multirow{2}{*}{$\begin{array}{l}\text { Employment } \\
\text { status }\end{array}$} & Employed & $22(51.2)$ & $24(54.5)$ & \multirow{2}{*}{$0.163^{* *}$} \\
\hline & Non-employment & $21(48.8)$ & $20(45.5)$ & \\
\hline \multirow[t]{2}{*}{ Education level } & High school and above & $19(44.2)$ & $16(36.4)$ & \multirow{2}{*}{$0.642 * *$} \\
\hline & Primary school & $24(55.9)$ & $28(63.6)$ & \\
\hline \multirow[t]{2}{*}{ Income status } & Adequate & $27(62.8)$ & $25(57)$ & \multirow{2}{*}{$0.532 * *$} \\
\hline & Inadequate & $16(37.2)$ & $19(43)$ & \\
\hline Duration & $1-5$ & $23(53.5)$ & $26(59)$ & \multirow{2}{*}{$0.614 * *$} \\
\hline of diabetes & $>5$ & $20(46.5)$ & $18(41)$ & \\
\hline
\end{tabular}

*Independent t-test; ** chi-square test

Table 2. Comparison of clinical parameters before and 4 months after the intervention in the two groups

\begin{tabular}{|c|c|c|c|c|}
\hline Variables & Time & $\begin{array}{l}\text { Intervention group } \\
(n=43)\end{array}$ & $\begin{array}{l}\text { Control group } \\
(n=44)\end{array}$ & $\begin{array}{l}\text { Independent } \\
\text { t-test }\end{array}$ \\
\hline \multirow[t]{3}{*}{ BMI } & Before & $29.31 \pm 5.8$ & $28.97 \pm 3.6$ & 0.25 \\
\hline & 4 months after & $27.82 \pm 4.5$ & $28.86 \pm 3.7$ & 0.001 \\
\hline & Paired $t$-test & 0.001 & 0.43 & \\
\hline \multirow[t]{3}{*}{ Systolic BP [mm Hg] } & Before & $138.5 \pm 5.4$ & $139.4 \pm 6.5$ & 0.57 \\
\hline & 4 months after & $126.7 \pm 3.8$ & $138.2 \pm 8.3$ & 0.001 \\
\hline & Paired $t$-test & 0.001 & 0.68 & \\
\hline \multirow[t]{3}{*}{ Diastolic BP [mm Hg] } & Before & $86.5 \pm 8.4$ & $88 \pm 2.3$ & 0.59 \\
\hline & 4 months after & $79 \pm 4.7$ & $89 \pm 7.8$ & 0.001 \\
\hline & Paired $t$-test & 0.001 & 0.76 & \\
\hline
\end{tabular}

$\mathrm{BMI}$ - body mass index; $\mathrm{BP}$ - blood pressure

study course. Their mean age was $51.97 \pm 6.3$ years, with the age range from 39 to 59 years. The two groups were humongous in terms of demographic information (age, sex, marital status, educational level, employment status, income status and duration of the disease) and there was no statistically significant difference between them (Table 1).

Table 2 compares the clinical parameters of the two groups before and after intervention. There was no significant difference between the two groups before the intervention period. The results showed a significant reduction in BMI, SBP and DBP in the intervention group. However, no significant difference was observed in the control group. Biochemical parameters included $\mathrm{HbA}_{1 \mathrm{c}^{\prime}}$ FBS, LDL, HDL, TC, TG, which were evaluated in Table 3.

Results of the independent $t$-test showed that there was no significant difference between the two groups in terms of mean biochemical parameters at the beginning of the intervention program. But comparing the mean biochemical parameters in the two groups showed that there was a significant difference between the intervention and control groups after the education period.

\section{Discussion}

Diet compliance and proper nutrition education are known as one of the elements that control diabetes [19]. Specialists begin the first line of diabetes treatment to modify lifestyle behaviors, especially changes in diet and physical activity. For many people with diabetes, acting and maintaining these behaviors is the most difficult aspect of self-care programs [20].

The management of DM does not only require prescriptions by physicians but also intensive education and counseling for the patients [21]. Diet counseling should be innovative and specific to personal needs [22]. 
Table 3. Comparison of biochemical parameters before and 4 months after the intervention in the two groups

\begin{tabular}{|c|c|c|c|c|}
\hline Variables & Time & $\begin{array}{l}\text { Intervention group } \\
(n=43)\end{array}$ & $\begin{array}{l}\text { Control group } \\
(n=44)\end{array}$ & $\begin{array}{l}\text { Independent } \\
\text { t-test }\end{array}$ \\
\hline \multirow[t]{3}{*}{$\mathrm{HbA}_{1 \mathrm{c}}(\%)$} & Before & $9.31 \pm 1.69$ & $9.49 \pm 1.76$ & 0.81 \\
\hline & 4 months after & $8.28 \pm 1.42$ & $9.51 \pm 1.63$ & 0.001 \\
\hline & Paired $t$-test & 0.001 & 0.62 & \\
\hline \multirow[t]{3}{*}{ FBS [mg/dL] } & Before & $166.8 \pm 28.5$ & $164.9 \pm 31.2$ & 0.78 \\
\hline & 4 months after & $141.5 \pm 16.7$ & $165.3 \pm 28.4$ & 0.001 \\
\hline & Paired $t$-test & 0.001 & 0.71 & \\
\hline \multirow[t]{3}{*}{ LDL [mg/dL] } & Before & $127.4 \pm 25.3$ & $129.9 \pm 21.6$ & 0.53 \\
\hline & 4 months after & $112.6 \pm 20.5$ & $132.8 \pm 19.7$ & 0.001 \\
\hline & Paired $t$-test & 0.001 & 0.07 & \\
\hline \multirow[t]{3}{*}{$\mathrm{HDL}[\mathrm{mg} / \mathrm{dL}]$} & Before & $49.2 \pm 17.9$ & $50.4 \pm 16.3$ & 0.72 \\
\hline & 4 months after & $62.4 \pm 9.8$ & $49.7 \pm 14.5$ & 0.001 \\
\hline & Paired $t$-test & 0.001 & 0.69 & \\
\hline \multirow[t]{3}{*}{$\mathrm{TC}[\mathrm{mg} / \mathrm{dL}]$} & Before & $181.7 \pm 9.4$ & $180.2 \pm 8.8$ & 0.59 \\
\hline & 4 months after & $164.2 \pm 8.6$ & $181 \pm 9.1$ & 0.001 \\
\hline & Paired $t$-test & 0.001 & 0.68 & \\
\hline \multirow[t]{3}{*}{ TG $[\mathrm{mg} / \mathrm{dL}]$} & Before & $200.6 \pm 74.7$ & $196.3 \pm 93.2$ & 0.83 \\
\hline & 4 months after & $164 \pm 68.9$ & $191.4 \pm 86.5$ & 0.001 \\
\hline & Paired $t$-test & 0.001 & 0.79 & \\
\hline
\end{tabular}

$\mathrm{HbA}_{1 \mathrm{c}}$ - hemoglobin $\mathrm{A}_{1 \mathrm{c}^{\prime}}$ FBS — fasting blood sugar; $\mathrm{LDL}$ - low-density lipoprotein; $\mathrm{HDL}$ — high density lipoprotein; TG — triglyceride; TC — total cholesterol

Studies have shown that controlling anthropometric and metabolic factors such as body weight, blood pressure, glucose, hemoglobin glycosylated, and lipid profiles play important roles in controlling diabetes [23]. Research also shows that nutrition education improves nutritional behavior and nutrition and modulates biochemical markers such as decreasing blood glucose and hemoglobin glycosylated levels, decreasing energy, fat, carbohydrates and protein intake [24, 25].

The research findings also indicate that educational intervention and nutrition counseling have been successful in improving the clinical and biochemical parameters of diabetic patients. The clinical parameters studied in this study included BMI, SBP, and DBP. The findings indicated that there was a significant decrease after 4 months of education and counseling.

Weight loss is one of the important therapeutic goals in T2DM patients [26]. In this study to achieve complete success, the diet were adjusted according to the needs and preferences of each individual. Educational content on healthy nutrition methods includes nutritional patterns with emphasis on balance and diversity and diet, high risk nutritional behaviors, pheromone recognition and how to use it, healthy eating plate, familiarity with harmful foods for diabetics and how to replace them with appropriate foods, advice on how to prepare and cook healthy foods, snacks, out- of-home eating strategies (restaurants, parties, on holidays), over-the-counter prevention methods, adherence to the diet plan, and advice on walking and physical activities that were prepared on the basis of authoritative scientific sources. Studies show that weight loss in obese or overweight diabetic patients, which is done through various therapies such as nutrition therapy, reduces insulin resistance, improves glycemic control criteria, lipid-lowering, and blood pressure reduction $[26,27]$. The results of Blonde et al. show that weight loss in overweight individuals leads to improved levels of $\mathrm{HbA}_{1 \mathrm{c}^{\prime}}$ FBS, TC, TG and SBP [28].

Blood pressure was another variable that was evaluated in this study. The prevalence of hypertension in T2DM patients is about $70 \%$, and the risk of growth of diabetes in people with high blood pressure is 2 times higher [29]. High blood pressure is one of the most important and common problems of diabetic patients which increases the risk of complications such as stroke, chronic kidney disease, heart disease, peripheral vascular disease, and death [30]. Treatment for high blood pressure in diabetes is necessary to prevent these complications [31]. Blood pressure control in diabetic patients is an important goal, and if an intervention can prevent the increase in the Systolic and Diastolic Blood Pressure of these patients, it is a success. Nowadays, the favorable blood pressure in patients with diabetes is considered to be $<130 / 80 \mathrm{~mm} \mathrm{Hg}$ [32]. 
The present research findings indicate that nutrition education and counseling have a good effect on the reduction of systolic and diastolic blood pressure in the intervention group. In confirmation of these results, Davies's study in Nepal showed that dietary training significantly reduced the patients' blood pressure [33].

In this study, the patients' $\mathrm{HbA}_{1 \mathrm{c}^{\prime}}$ FBS and lipid profile were also evaluated. The results indicate that there is a significant improvement in the average of all of these variables after education and counseling.

Diabetes is associated with major changes in lipid and its components in plasma. In uncontrolled type 2 diabetes, an increase in LDL, TC, TG, and HDL reduction is observed, which ultimately results in coronary artery disease (CAD) [34].

Research has shown that there is a strong correlation between hypercholesterolemia and cardiovascular disease, with a reduction in LDL of $1 \mathrm{mg} / \mathrm{dL}$, resulting in a $1-2 \%$ reduction in the probability of a relative risk of cardiovascular disease [35].The most common form of dyslipidemia in T2DM patients is the increase in triglyceride levels and HDL reduction [36].

Jafari et al. conducted a study entitled "effectiveness of nutrition education using electronic methods on blood glucose and lipid control in T2DM patients" whose results showed that educational intervention effectively reduced blood glucose and lipids in patients [37]. Parizad et al. found that training had important effects on the control of laboratory parameters $\left(\mathrm{HbA}_{1 c^{\prime}}\right.$ FBS, TC, TG and insulin level) in T2DM patients [38]. Davis et al. showed that blood cholesterol level in the intervention group was significantly reduced for 12 months after training, and this decrease was statistically significant [39]. Rodriguez et al. (2009) showed a statistically significant decrease in cholesterol and triglyceride levels in the intervention group [40].

In a study conducted by Doostan et al. in order to evaluate the effect of clinical nutritional education on blood glucose control and serum lipids in T2DM patients. The results indicated that nutrition education in patients undergoing effective control of their serum lipids $\mathrm{HbA}_{1 c^{\prime}}$ and FBS [41]. Wilson et al. investigated the effectiveness of clinical nutrition education and the regularity of education on glycemic control in T2DM patients and found that patients trained by a nutritionist were more likely to be improved in terms of the $\mathrm{HbA}_{1 \mathrm{c}}$ level than those trained by nonspecialists. Moreover, proper nutritional education showed a good relationship with glycemic control [42]. Kashfiet al. showed that diet and walking training in diabetic patients significantly reduced the $\mathrm{HbA}_{1 \mathrm{c}}$ and FBS in the intervention group compared to the control group [10].
Other studies, including Scain et al. [43] and Kyzer et al. [44], also indicated a significant decrease in $\mathrm{HbA}_{1 \mathrm{c}}$ levels after educational intervention, which are consistent with the results of the present study. Similar results were obtained in Moradi et al. [3, 4].

\section{Conclusion}

The research findings indicate that the implementation of group training program, along with individual nutrition counseling, is very effective and can lead to weight loss, improved blood pressure and better control of blood glucose and lipids in T2DM patients. Therefore, in addition to routine training, patients need to receive education and counseling based on a planned program. Training and counseling are complementary. In the treatment and control of diseases such as diabetes, which is the responsibility and primary responsibility of the patient, it is essential to succeed in achieving better results and better metabolic control in patients with education.

\section{Acknowledgments}

The authors are grateful to all patients as well as community health centers staff who helped us with this study.

\section{Conflict of interest}

The authors report no conflicts of interest in this study.

\section{REFERENCES}

1. Savira M, Amelia R. The effect of diabetes self-management education on $\mathrm{HbA} 1 \mathrm{c}$ level and fasting blood sugar in type 2 diabetes mellitus patients in primary health care in Binjai City of North Sumatera, Indonesia. Open Access Maced J Med Sci. 2018; 6(4): 715-718, doi: 10.3889/oamjms.2018.169, indexed in Pubmed: 29731946.

2. Moradi A, Morovati HR, Teimourpour A, et al. Determine the prevalence of gestational diabetes in Ardakan and its related factors. MethodsX. 2019; 6: 409-416, doi: 10.1016/j.mex.2019.02.016, indexed in Pubmed: 30899677.

3. Seuring T, Archangelidi O, Suhrcke M. The economic costs of type 2 diabetes: a global systematic review. Pharmacoeconomics. 2015; 33(8): 811-831, doi: 10.1007/s40273-015-0268-9, indexed in Pubmed: 25787932.

4. Moradi A, Alavi SM, Salimi M, et al. The effect of short message service (SMS) on knowledge and preventive behaviors of diabetic foot ulcer in patients with diabetes type 2. Diabetes Metab Syndr. 2019; 13(2): 1255-1260, doi: 10.1016/j.dsx.2019.01.051, indexed in Pubmed: 31336474.

5. McDuffie RH, Struck L, Burshell A. Empowerment for diabetes management: integrating true self-management into the medical treatment and management of diabetes mellitus. Ochsner J. 2001; 3(3): 149-157, indexed in Pubmed: 22754392.

6. Larijani B, Forouzandeh F. Forouzandeh F. Diabetic foot disorders. ijdld. 2003; 2(2): 93-103.

7. LeRoith D, Taylor S, Olefsky J. Diabetes mellitus. A fundamental and clinical text 3, editor. Lippincott Williams and Wilkins, Philadelphia 2004 
8. Ojieabu W, Bello S, Arute J. Evaluation of pharmacists' educational and counselling impact on patients' clinical outcomes in a diabetic setting. J Diabetol. 2017; 8(1): 7-11, doi: 10.4103/jod.jod_5_17.

9. Pendsey S. Practical management of diabetes. 2nd ed. Hoboken. Wiley, New York 2002.

10. Kashfi SM, Khanijyhouni A, Bahadorikhalili R, et al. Evaluation of the effects of educating about nutrition and jogging on the blood sugar of type II diabetic patients of a clinic in Shiraz, Iran. Hakim Health Sys Res. 2009; 12(3): 54-60.

11. Monahan FD, Phipps WJ. Phipps' medical-surgical nursing: health and illness perspectives: Recording for the Blind \& Dyslexic 2008.

12. Amini N, BayaT F, Bekri G, et al. Effect of education on knowledge, attitude and nutritional behavior of patients with type 2 diabetes. Health Develop J. 2012; 1(4): 306-314.

13. Sadeghi M, Nikbakht Nasrabadi AR, Ebrahimi $H$, et al. The effect of family-centered empowerment model on knowledge and metabolic control of patients with type 2 diabetes. Journal of Knowledge \& Health. 2014; 9(1): 48-54.

14. Norris S, Nicholas $P$, Caspersen $C$, et al. Increasing diabetes selfmanagement education in community settings: a systematic review. Am J Prev Med. 2002; 22(4): 39-66, doi: 10.1016/s07493797(02)00424-5.

15. Dunning T. Care of people with diabetes: a manual of nursing practice. 2nd edition. Blackwell Publishing, Carlton South (UK). 2003

16. Firooz M, Mazloom SR, Kimiae SA, et al. Comparing the effect of group education versus group counseling for self-care on glycated-hemoglobin in patients with diabetes type II. J Mazandaran Univ Med Sci. 2015; 25(124): 26-36.

17. Neyestani TR. Manual of clinical nutrition and diet therapy Adults with diabetes. Ministry of Health and Education of Iran. 2015.

18. Sheykh F. Manual of Diet Therapy: Iranian nutrition Society. 2nd ed. Salemi Publication, Tehran 2003: 206-210.

19. Skamagas $M$, Breen TL, LeRoith D. Update on diabetes mellitus: prevention, treatment, and association with oral diseases. Oral Dis. 2008; 14(2): 105-114, doi: 10.1111/j.1601-0825.2007.01425.x, indexed in Pubmed: 18302671.

20. Yeaw J, Lee WC, Aagren M, et al. Cost of self-monitoring of blood glucose in the United States among patients on an insulin regimen for diabetes. J Manag Care Pharm. 2012; 18(1): 21-32, doi: 10.18553/jmcp.2012.18.1.21, indexed in Pubmed: 22235952.

21. Kyriazis I, Mendrinos D, Rekleiti M, et al. Diabetic patients are often sub-optimally aware about their disease and its treatment. Int J Caring Sci. 2013; 6(1): 53-58.

22. Connor H, Annan F, Bunn E, et al. Nutrition Subcommittee of the Diabetes Care Advisory Committee of Diabetes UK. The implementation of nutritional advice for people with diabetes. Diabet Med. 2003; 20(10): 786-807, doi: 10.1046/j.1464-5491.2003.01104.x, indexed in Pubmed: 14510859.

23. Yuan C, Lai CWK, Chan LWC, et al. The effect of diabetes selfmanagement education on body weight, glycemic control, and other metabolic markers in patients with type 2 diabetes mellitus. J Diabetes Res. 2014; 2014: 789761, doi: 10.1155/2014/789761, indexed in Pubmed: 25136645.

24. Malek M, Cakiroglu P. The effects of nutritional education on patients with type II diabetes on the nutritional knowledge and consumption. European Journal of Experimental Biology. 2013; 3(1): 217-222.

25. Lim HM, Park JE, Choi YJ, et al. Individualized diabetes nutrition education improves compliance with diet prescription. Nutr Res Pract. 2009; 3(4): 315-322, doi: 10.4162/nrp.2009.3.4.315, indexed in Pubmed: 20098585.

26. Redmon JB, Reck KP, Raatz SK, et al. Two-year outcome of a combination of weight loss therapies for type 2 diabetes. Diabetes Care. 2005; 28(6): 1311-1315, doi: 10.2337/diacare.28.6.1311, indexed in Pubmed: 15920044.
27. Ybarra J, James RW, Makoundou V, et al. Effects of short-term modest weight loss on fasting and post-prandial lipoprotein subfractions in type 2 diabetes mellitus patients. Diabetes Metab. 2001; 27(6): 701-708, indexed in Pubmed: 11852380.

28. Blonde L, Pencek R, MacConell L. Association among weight change, glycemic control, and markers of cardiovascular risk with exenatide once weekly: a pooled analysis of patients with type 2 diabetes. Cardiovasc Diabetol. 2015; 14: 12, doi: 10.1186/ s12933-014-0171-2, indexed in Pubmed: 25645567.

29. Shahdadi $H$, Mansouri A, Dashtban RA. comparative study on the effect of garlic and cumin on blood pressure in patients with type 2 diabetes: a clinical double-blind trial. J Urmia Nurs Midwifery Fac. 2017; 15(8): 605-611.

30. Colosia AD, Palencia R, Khan S. Prevalence of hypertension and obesity in patients with type 2 diabetes mellitus in observational studies: a systematic literature review. Diabetes Metab Syndr Obes. 2013; 6: 327-338, doi: 10.2147/DMSO.S51325, indexed in Pubmed: 24082791.

31. Chiha M, Njeim M, Chedrawy EG. Diabetes and coronary heart disease: a risk factor for the global epidemic. Int J Hypertens. 2012; 2012: 697240, doi: 10.1155/2012/697240, indexed in Pubmed: 23119148.

32. Shahbodaghi Z, Borhani F, Rayani M. The effects of self-care program on blood pressure of patients with diabetes. Medical - Surgical Nursing Journal. 2014; 3(3): 163-169.

33. Davies TM. Hypertension, and fruits and vegetables in Nepal: an evidence based review. Virginia Henderson Global Nursing e-Repository 2015.

34. Arvind K, Pradeepa R, Deepa R, et al. Diabetes \& coronary artery disease. Indian J Med Res. 2002; 116: 163-176, indexed in Pubmed: 12710546.

35. Mahan KL, Stump ES, Raymond JL. Krause's Food, Nutrition \& Diet therapy. 13th ed. Saunders 2012.

36. Steinmetz A. Treatment of Diabetic Dyslipoproteinemia. Exp Clin Endol Diabetes. 2003; 111(05): 239-245, doi: 10.1055/s2003-41748.

37. Jafari M, Pasdar $Y$, Rezaei $M$, et al. Effect of nutrition education using electronic methods on blood lipids and glucose in type II diabetic patients. IJHLS. 2015; 1(2): 8-13.

38. Parizad N, HemmatiMaslakpak M, Khalkhali HR. The effect of teleeducation by telephone and short message service on laboratory parameters in patients with type 2 diabetes. Journal of Ardabil University of Medical Sciences. 2014; 14(1): 7-17.

39. Davis RM, Hitch AD, Salaam MM, et al. TeleHealth improves diabetes self-management in an underserved community: diabetes TeleCare. Diabetes Care. 2010; 33(8): 1712-1717, doi: 10.2337/ dc09-1919, indexed in Pubmed: 20484125.

40. Rodríguez-Idígoras M, Sepúlveda-Muñoz J, Sánchez-GarridoEscudero $R$, et al. Telemedicine influence on the follow-up of type 2 diabetes patients. Diabetes Tech Therapeut. 2009; 11(7): 431-437, doi: 10.1089/dia.2008.0114.

41. Doostan F, Lashkari T. The effect of clinical nutrition education on blood glucose and serum lipids control: A study on type II diabetic patients referred to diabetes center of ShahidBahonar hospital, Kerman, Iran. Journal of Health \& Development. 2016; 5(1): 79-89.

42. Wilson C, Brown T, Acton K, et al. Effects of clinical nutrition education and educator discipline on glycemic control outcomes in the Indian health service. Diabetes Care. 2003; 26(9): 2500-2504, doi: 10.2337/diacare.26.9.2500, indexed in Pubmed: 12941709.

43. Scain SF, Friedman R, Gross JL. A structured educational program improves metabolic control in patients with type 2 diabetes: a randomized controlled trial. Diabetes Educ. 2009; 35(4): 603-611, doi: 10.1177/0145721709336299, indexed in Pubmed: 19451553.

44. Kyzer H, Hakkak R, Caroll P, et al. Effectiveness of outpatient diabetes education on HbA1C levels. The FASEB Journal. 2008; 22: 872-874. 